Bangl. J. Vet. Med. (2011). 9 (2): 177 - 182

\title{
PREVALENCE OF GIARDIA LAMBLIA INFECTION IN CHILDREN AND CALVES IN
} BANGLADESH

\author{
M. S. H. Suman', M. M. Alam¹, S. B. Pun², A. Khair ${ }^{1}$, S. Ahmed ${ }^{4}$ and R. Y. Uchida ${ }^{3}$ \\ ${ }^{1}$ Department of Medicine, Faculty of Veterinary Science, Bangladesh Agricultural University, Mymensingh \\ ${ }^{2}$ Clinical Research Unit, Sukraraj Tropical and Infectious Disease Hospital, Teku, Kathmandu, Nepal \\ ${ }^{3}$ Department of Respiratory Medicine and Infectious Diseases, Kusatsu General Hospital, 1660, Yabase-cho, \\ Kusatsu City, Shiga-prefecture, 525-8585, Japan \\ ${ }^{4}$ Department of Pediatrics, Institute of Child and Mother Health, Matuail, Dhaka-1362, Bangladesh
}

\begin{abstract}
Giardia lamblia is highly infectious protozoan parasite capable of causing gastrointestinal illness in both humans and animals. The objective of this study was to determine the prevalence of Giardia lamblia infection in children $<5$ years old and calves. Enzyme Linked Immunosorbent Assay (ELISA) has been used for the detection of Giardia lamblia. A total of 266 children and 15 calves diarrheic fecal samples were tested for Giardia lamblia during January 2011 to May 2012. The prevalence of Giardia lamblia infection among children was 3.8\% while $13.3 \%$ in calves. Giardia lamblia was highest in children between 24 and 60 months of age (8.7\%). Giardia lamblia infection was higher in male (4.7\%) than in female (2.0\%). Male calves (14.3\%) have slightly higher prevalence than female calves (12.5\%). The highest prevalence (33.3\%) of Giardia lamblia infection in calves was between the ages 6 and 9 months. This is the first study to determine the prevalence of Giardia lamblia infection in calves using ELISA method in Bangladesh. A larger scale study is needed for accurate estimates of prevalence of Giardia lamblia to undertake an appropriate control strategy in future.
\end{abstract}

Key words: Giardia lamblia; Children diarrhea; Calves diarrhea; ELISA; Prevalence.

\section{INTRODUCTION}

The intestinal protozoan parasite, Giardia labmlia (Syn. Giardia intestinalis, Giardia duodenalis) has recently emerged as an important cause of diarrhoea in humans and animals. It is distributed worldwide and presents high levels of genetic diversity. In developing countries, about 200 million people have symptomatic giardiasis with some 500,000 new cases reported each year (WHO, 1996). The disease is most common in areas where sanitation and hygiene are poor (Nygard et al., 2006). Increased prevalence in human as well as in some of the surrounding animals offers an emerging concern about the role played by some animals in human giardiasis (Olson, 2004). Each individual eliminates up to 900 million cysts per day. Higher prevalence is found in tropical and subtropical areas, in urban than in rural where Giardia labmlia affects up to $30 \%$ of the population (Minvielle et al., 2004). A previous study has found Giardia lamblia in 68\% of children aged between 2 to 8 months in Bangladesh (Hall, 1994). Haque et al. (2003) reported 11.08\% Giardia lamblia infection in 2-5 years old group in Mirpur, an urban slum area in Dhaka. In Bangladesh several studies has been performed to determine the prevalence of Giardia lamblia (Haque et al., 2003; Alam et al., 2011) by direct microscopic examination. Very few researches have been conducted by modern diagnostic techniques like immunofluorescence assay, enzyme-linked immunosorbent assay (ELISA) or polymerase chain reaction (PCR). There is a need for a sensitive and specific diagnostic procedure for screening Giardia lamblia. ELISA has greater sensitivity and specificity than the conventional diagnosis techniques (eg. direct microscopic examination) (McGlade et al., 2003). ELISA test detect soluble antigens in the feces. A number of commercial coproantigen capture enzyme linked immunosorbent assay (ELISA) based tests (Dryden et al., 2006) have been shown to have higher sensitivities than zinc flotation and microscopy for the detection of Giardia lamblia. There is no published data on the prevalence of Giardia lamblia infection using ELISA in calves in Bangladesh. The present research work was undertaken to determine the prevalence of Giardia lamblia infection in children and calves in Bangladesh using Sandwich-ELISA. 


\section{S. H. Suman and others}

\section{MATERIALS AND METHODS}

\section{Sample collection}

The present study was carried out during January 2011 to May 2012 in the Laboratory, Department of Medicine, Bangladesh Agricultural University (BAU), Mymensingh, Bangladesh. Stool specimens were collected from hospitalized children admitted to Institute of Children and Maternity Hospital (ICMH), Matuail, Dhaka. Calves specimens were collected from Bangladesh Agricultural University (BAU) and surrounding areas of Mymensingh. Specimens were collected from rectum of calves inserting fingers equipped with thin rubber hand gloves and were collected in sterile screw capped containers. Five to ten grams of stool specimen was collected. Precautions were taken to avoid contamination from one specimen to the other. The samples were then transferred to the container containing ice bag and stored at -200C as quickly as possible and transported to the laboratory of the department of Medicine at BAU. Information about the age, sex, clinical signs and symptoms and date of collection was recorded.

\section{Preparation of Sample (Fresh/Frozen Stools)}

Frozen specimens were thawed at room temperature and 1:4 dilutions of the specimens were prepared in eppendorf tube by using $0.3 \mathrm{ml}$ of dilution buffer (approximately $0.1 \mathrm{~g}$ ). In case of watery specimens, $0.1 \mathrm{ml}$ of specimen was added to $0.3 \mathrm{ml}$ dilution buffer in eppendorf tubes. In case of semisolid specimens, samples were centrifuged at 2000-3000 rpm for 5-10 minutes to produce clear supernatant.

\section{Method}

Enzyme Linked Immunosorbent Assay (Sandwich, Antibody Coated Plate, Diagnostic Automation, Inc. USA)

\section{Interpretation of results}

Results were estimated visually by naked eye.

Reactive: Sample well that is obviously more yellow than the negative control well.

Non-reactive: Sample well that is not obviously more yellow than the negative control well.

\section{Statistical analysis}

The data was entered in Microsoft Excel 2007 and transferred to R 2.14.2 (The R Foundation for Statistical Computing, Vienna, Austria) for descriptive and analytical statistics. Bivariable logistic regression method was used to determine any association between age and sex of humans with Giardia lamblia infection in R.

\section{RESULTS AND DISCUSSION}

A total of 266 children and 15 calves specimens were examined to determine the prevalence of Giardia lamblia infection in Bangladesh. The prevalence of Giardia lamblia infection among hospitalized diarrheic children was found to be $3.8 \%$ and $13.3 \%$ in calves. The prevalence of Giardia lamblia infection in children and calves is presented in Table 1.

Table 1. Prevalence of Giardia lamblia infection in human and calves

\begin{tabular}{|ccccc|}
\hline Species & No. tested & No. positive & Prevalence (\%) & 95\% Confidence Interval \\
\hline Human & 266 & 10 & 3.8 & $1.8-6.8$ \\
Calves & 15 & 2 & 13.3 & $1.7-40.5$ \\
\hline
\end{tabular}

The prevalence of Giardia lamblia infection was highest (8.7\%) in children between 24 to 60 months of age although it was not statistically significant. The age wise distribution of Giardia lamblia infection in children is presented in Table 2. 
Table 2. Age specific distribution of Giardia lamblia infection in hospitalized children with diarrhea in ICMH, Dhaka

\begin{tabular}{|c|c|c|c|c|c|c|}
\hline $\begin{array}{l}\text { Age in groups } \\
\text { (months) }\end{array}$ & No. tested & No. positive & Prevalence (\%) & $\begin{array}{c}\text { 95\% Confidence } \\
\text { Interval (CI) of } \\
\text { Prevalence } \\
\end{array}$ & $\begin{array}{l}\text { Odds Ratio } \\
\text { (OR) }\end{array}$ & $95 \%$ CI of OR \\
\hline$<6$ months & 11 & 0 & 0 & $0-28.5$ & Ref. & Ref. \\
\hline 6-12 months & 141 & 3 & 2.1 & $0.4-6.1$ & 2.34 & 0 , Infinity \\
\hline $\begin{array}{c}13-24 \\
\text { months }\end{array}$ & 91 & 5 & 5.5 & $1.8-12.4$ & 6.08 & 0 , Infinity \\
\hline 25-60 months & 23 & 2 & 8.7 & $1.1-28.0$ & 1.01 & 0 , Infinity \\
\hline Total & 266 & 10 & 3.8 & $1.8-6.8$ & - & - \\
\hline
\end{tabular}

Table 3. Age specific distribution of Giardia lamblia infection in calves

\begin{tabular}{|ccccc|}
\hline $\begin{array}{c}\text { Age in groups } \\
\text { (months) }\end{array}$ & No. tested & No. positive & Prevalence (\%) & 95\% Confidence Interval \\
\hline$<3$ months & 3 & 0 & 0 & $0-70.8$ \\
$3-6$ months & 5 & 1 & 20 & $0.5-71.6$ \\
$7-9$ months & 3 & 1 & 33.33 & $0.8-90.6$ \\
$10-12$ months & 4 & 0 & 0 & $0-60.2$ \\
Total & $\mathbf{1 5}$ & $\mathbf{2}$ & $\mathbf{1 3 . 3}$ & $\mathbf{1 . 7}-\mathbf{4 0 . 5}$ \\
\hline
\end{tabular}

Sex wise distribution of Giardia lamblia infection in children and calves is shown in Table 4 and 5. Males were at higher risk for developing Giardia infection compared to females both in children and calves.

Table 4. Sex specific distribution of Giardia lamblia infection in hospitalized children with diarrhea in ICMH, Dhaka

\begin{tabular}{|cccccc|}
\hline Sex & No. tested & No. positive & Prevalence (\%) & Odds Ratio & 95\% Confidence Interval \\
\hline Female & 97 & 2 & 2.1 & Reference & Reference \\
Male & 169 & 8 & 4.7 & 2.21 & $0.46-10.8$ \\
Total & $\mathbf{2 6 6}$ & $\mathbf{1 0}$ & $\mathbf{3 . 8}$ & - & $\mathbf{1 . 8}-\mathbf{6 . 8}$ \\
\hline
\end{tabular}

Table 5. Sex specific distribution of Giardia lamblia infection in calves

\begin{tabular}{|ccccc|}
\hline Sex & No. tested & No. positive & Prevalence (\%) & 95\% Confidence Interval \\
\hline Male & 7 & 1 & 14.3 & $0.4-57.8$ \\
Female & 8 & 1 & 12.5 & $0.3-52.7$ \\
Total & $\mathbf{1 5}$ & $\mathbf{2}$ & $\mathbf{1 3 . 3}$ & $\mathbf{1 . 7}-\mathbf{4 0 . 5}$ \\
\hline
\end{tabular}




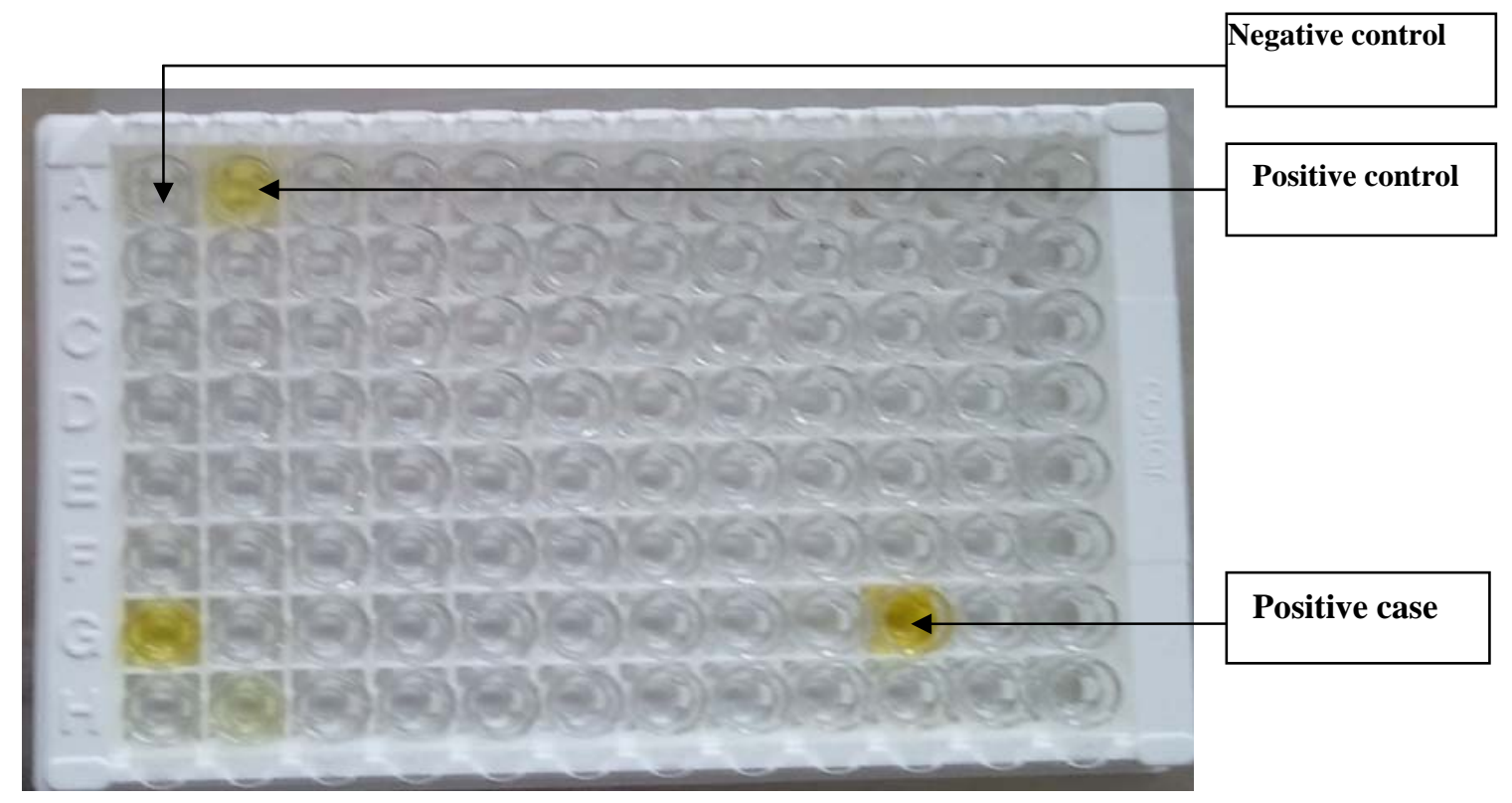

Figure 1. Microwells containing anti-Giardia antibodies - 96 test wells in a test strip Holder

In the present study, the prevalence of Giardia lamblia infection was $3.8 \%$ in children. In contrast to this study, Haque et al. (2003) reported higher prevalence (11\%) in children living in the urban slum areas. These two studies have different settings, one based on hospitalized diarrheic patients and the other on slum dwellers. Overcrowding, lack of personal hygiene and sanitary conditions of the area, contaminated drinking water, may be responsible for higher prevalence of Giardia lamblia infection in slum areas. However, the prevalence of this study was in accordance with previous studies (Ngan et al., 1992; Verle et al., 2003).

Bjorkman et al. (2003) estimated 3.1\% (1.5\%-5.3\%) Giardia lamblia infection in children by immunological assay (ELISA) is in agreement with the present findings. However, Alam et al. (2011) and Guillermo et al. (2011) found contrary to the present study though same diagnostic technique has been used. It may be due to different study area, sample size, age group etc. As microscopical examination has some disadvantage (time consuming and sensitivity could be affected by intermittent excretion of intestinal parasites), ELISA is more preferable for rapid diagnosis of large size sample.

The prevalence of Giardia lamblia infection in children was highest (8.7\%) between 24 to 60 months of age was similar to the previous studies (Haque et al., 2003). The possible reasons for this age dependent pattern are probably related to children habits (e.g. sharing things among themselves, putting objects into the mouth). Another reason for higher infections in children may also be related to the lack of effective immunity.

Studies in India and Nigeria have shown that boys were more likely to be infected with the Giardia lamblia than girls (Ranjan et al., 2004; Dewivedi et al., 2007) which is similar to our findings. Male was associated with a significantly higher relative risk for the first episode of symptomatic giardiasis.

Giardia has the potential to cause clinical disease in calves and to be transmitted to other animal species and humans, detection of Giardia lamblia in calves therefore may be of great public health significance, as humans and animals share sometimes the same premises in rural settings. About $13.3 \%$ calves were found to be infected with Giardia lamblia in our study. Similar observations were also made by others (Huetink et al., 2001; Appelbee et al., 2003). However, higher prevalence of Giardia lamblia infection was reported by other studies (Gow et al., 2006; Geurden et al., 2008). This difference may be due to sample size and diagnostic techniques. 
This is the first study about the prevalence of Giardia lamblia infection in calves in Bangladesh by SandwichELISA method. A greater awareness of parasitic contamination of the environment and its impact on health has precipitated the development of better detection methods for Giardia lamblia. The pathological study and seasonal dynamics on prevalence of Giardia lamblia is not yet studied which would be more effective in treatment and control measure against the Giardia lamblia infection in humans and calves, so a large scale study is needed in order to get accurate estimation of both in humans and animals for implementing effective control measures of Giradia lamblia in future.

\section{REFERENCES}

1. Alam MM, Ilias M, Siddiqua MA, Kabir MM, Nazib F and Khan GM (2011). Genotype-specific detection of Giardia lamblia in stool samples of diarrhoeal patients in Dhaka, Bangladesh. Dhaka University Journal of Biological Science 20: 183-189.

2. Appelbee AJ, Frederick LM, Heitman TL and Olson ME (2003). Prevalence and genotyping of Giardia duodenalis from beef calves in Alberta, Canada. Veterinary Parasitology 112: 289-294.

3. Bjorkman C, Svensson C, Christensson B and de Verdier K (2003). Cryptosporidium parvum and Giardia intestinalis in Calf Diarrhoea in Sweden. Acta Veterinaria Scandinavica 44: 145-152.

4. Dryden MW, Payne PA and Smith V (2006). Accurate diagnosis of Giardia spp and proper fecal examination procedures. Veterinary Therapeutics 7: 4-14.

5. Dwivedi KK, Prasad G, Saini S, Mahajan S, Lal S and Krishan U (2007). Enteric opportunistic parasites among HIV infected individual: associated risk factors and immune status. Japan Journal of Infectious Disease 60: 76-81.

6. Garcia LS, Shimizu RY, Novak S, Carroll M and Chan F (2003). Commercial assay for detection of Giardia lamblia and Cryptosporidium parvum antigens in human fecal specimens by rapid solid-phase qualitative immunochromatography. Journal of Clinical Microbiology 41: 209-212.

7. Geurden T, Geldhof P, Levecke B, Martens C, Berkvens D, Casaert S, Vercruysse J and Claerebout E (2008). Mixed Giardia duodenalis assemblage A and E infections in calves. International Journal of Parasitology 38: 259-264.

8. Gow S and Waldner C (2006). An examination of the prevalence of and risk factors for shedding of Cryptosporidium spp. and Giardia spp. in cows and calves from western Canadian cow-calf herds. Veterinary Parasitology 137: 50-61.

9. Guillermo A, Cardonaa AG, Carabinb H, Gonic P, Arriolad L, Robinsone G, Fernández-Crespof JC, Clavelc A, Chalmerse RM and Carmenag D (2011). Identification and molecular characterization of Cryptosporidium and Giardia in children and cattle populations from the province of Alava, North of Spain. Science of the Total Environment 412-413: 101-108.

10. Hall A (1994). Giardia infections: epidemiology and nutritional consequences. In: Giardia: From Molecules to Disease, Thompson RCA, Reynoldson JA and Lymbery AJ 2nd eds., pp. 251-279 Cab International, Wallingford, UK.

11. Haque R, Mondal D, Kirkpatrick BD, Akther S, Farr BM, Sack RB and Petri WA (2003). Epidemiologic and clinical characteristics of acute diarrhea with emphasis on Entamoeba histolytica infections in preschool children in an urban slum of Dhaka, Bangladesh. American Journal of Tropical Medicine and Hygiene 69: 398-405.

12. Huetink RE, van der Giessen JW, Noordhuizen JP and Ploeger HW (2001). Epidemiology of Cryptosporidium spp and Giardia duodenalis on a dairy farm. Veterinary Parasitology 102: 53-67.

13. McGlade TR, Robertson ID, Elliot AD and Thompson RC (2003). High Prevalence of Giardia detected in cats by PCR. Veterinary Parasitology 110: 197-205.

14. Minvielle M, Pezzani B, de Luca M, Apezteguia M and Basualodo J (2004). Epidemiological survey of Giardia spp. and B. hominis in an Argentinian rural community. Korean Journal of Parasitology 42: 61-66. 


\section{S. H. Suman and others}

15. Ngan PK, Khanh NG, Tuong CV, Quy PP, Anh DN and Thuy HT (1992). Persistent diarrhea in Vietnamese children: a preliminary report. Acta Paediatrica 381:124-6.

16. Nygard K, Schimmer B and Sobstrad O (2006). A large community outbreak of waterborne giardiasisdelayed detection in a non-endemic urban area. BMC Public Health 6: 141-141.

17. Olson ME (2004). Zoonotic protozoan parasites in cattle emerging issues. Proceeding of the WBC Congress, Quebec, Canada.

18. Ranjan P, Ghoshal UC, Aggarwal R, Pandey R, Misra A, Naik S and Naik SR (2004). Etiological spectrum of sporadic malabsorption syndrome in northern Indian adults at a tertiary hospital. Indian Journal of Gastroenterology 23: 94-98.

19. Verle P, Kongs A, De NV, Thieu NQ, Depraetere K, Kim HT and Dorny P (2003). Prevalence of intestinal parasitic infections in northern Vietnam. Tropical Medicine of International Health 8: 961-964.

20. World Health Organization (WHO). (1996). The World Health Report -1996, Fighting Disease Fostering Development, Geneva. 